\title{
DRUGS IN THE TREATMENT OF RHEUMATIC DISORDERS
}

\author{
BY \\ N. MUTCH
}

Drugs are important in the treatment of rheumatic diseases, but the role they play is essentially a contributory one, to be fitted carefully into the general therapeutic plan. Their greatest uses are to be found in acute rheumatic fever and its clinical variants, in gout, non-articular fibrositis, and those forms of chronic arthritis, typified by rheumatoid arthritis, in which intermittently progressive inflammatory lesions are produced in joints which have become subtly potentiated or in joints which have been involved during acute bacterial infections. The group includes joints in which the lesions of chronic inflammation are modified by those of coincident growth, senescence trauma, osteo-arthritis, _and gout.

\section{Rheumatic Fever}

Salicylates, used since 1876, maintain the foremost place in the treatment of this disease. Their striking clinical effects still lack pharmacological explanation. Rheumatic pain is thought to be caused by local exudates which arise from capillary damage produced by histamine. Swyer (1948) has shown that the wheal which follows the intradermal injection of histamine does not form in subjects taking salicylates, and has so provided some evidence that salicylates may act by antagonizing the effects of local histamine-release near the joints. Hyaluronidase also is suspected of being concerned in the production of rheumatic effusions. The ferment is present in many tissues and in haemolytic streptococci. It hydrolyses hyaluronic acid and promotes the diffusion of bacteria and their products through connective tissues. Experimentally when injected intradermally with Evans Blue it causes rapid dispersal of the latter. Guerra and Gil (1946, 1947) found by this test that rheumatic fever patients are particularly sensitive to hyaluronidase and that the reaction could be prevented by the prior administration of salicylates. Swyer could not confirm this latter observation and suggested the Guerra's solutions might have been contaminated with histamine. The idea, however, still remains plausible that the rapidly formed effusions of acute rheumatic fever result from the combined effects of capillary damage by histamine and the diffusion of toxins by hyaluronidase, and that salicylates give clinical relief by inhibiting the effects of the former process. Whilst there is universal agreement that salicylates reduce the fever, joint swelling, and pain of rheumatic fever, it still remains uncertain how far the drug can eradicate the disease itself or even benefit the rheumatic heart. After much research their claim to act as true chemotherapeutic agents remains unproven. Salicylic acid is o-hydroxybenzoic acid. Its $m$ - and $p$-isomers are therapeutically inactive; but gentisic acid, which is 2,5,-dehydroxybenzoic acid has some influence over acute rheumatic fever. Meyer and Ragan (1948) consider its sodium salt to be as effective as sodium salicylate in this condition and see a mutual relationship between the clinical effect of sodium gentisate and its inhibitory action in vitro on the diffusing factor.

Sodium Salicylate.-Modern methods of analysis now enable clinical phenomena to be more accurately correlated with salicylate concentrations in the blood. Sodium salicylate taken by mouth is quickly absorbed and attains a peak concentration in the plasma after two hours. To prevent any dip in the graph of successive plasma concentrations the dosage interval must not be greater than two hours. Elimination takes place much more slowly than absorption, and on a two-hourly dosage scheme cumulation occurs so that the plasma concentration curve shows a steady rise instead of the desired plateau. If large individual doses are repeated, toxic symptoms will inevitably arise. Their onset should be carefully noted and the dose adjusted. Some salicylism always occurs before the full therapeutic effect on joints and fever has been attained, but in chemotherapeutic tests higher degrees of intoxication have been induced, bordering on the fatal. One of the earliest warning symptoms is hyperpnoea resembling that of diabetic acidosis. More serious still are delirium and coma. Bowen and others (1936) reported that often the $\mathrm{CO}_{2}$ carrying power of the blood is not materially affected. Gebert (1931) found that $p \mathrm{H}$ values might indeed sometimes be raised so that the administration of alkalis cannot be expected entirely to alleviate the condition.

Coburn (1943) was the first to publish controlled 
observations on massive salicylate therapy, and he stated that plasma levels of $35 \mathrm{mg}$. of salicylate per $100 \mathrm{ml}$. were sufficient to suppress infection, shorten the period of illness, decrease the relapse rate, and prevent serious heart involvement. Warren and others (1946) found that in young adults a daily dose of $7 \mathrm{~g}$. to $8 \mathrm{~g}$. was required to establish such concentrations. Manchester (1946) confirmed Coburn's findings. He injected a litre of 1 per cent. sodium salicylate solution intravenously each day for four to ten days, after which $10 \mathrm{~g}$. daily combined with $8 \mathrm{~g}$. of sodium bicarbonate were given by mouth on a four-hourly plan. Reid (1948) thought that some curative effect could be seen in his small series of twelve patients in whom he secured plasma salicylate levels of $20 \mathrm{mg}$. to $46 \mathrm{mg}$. per $100 \mathrm{ml}$.

The severe degree of poisoning frequently induced by such technique would be justified if there were full assurance that the incidence of cardiac lesions could indeed be reduced, but other observers have not been so fortunate. Warren and others (1946), using graded dosage schemes (1) $2 \mathrm{~g}$. to $7 \mathrm{~g}$. daily, (2) $10 \mathrm{~g}$. to $16 \mathrm{~g}$. daily, (3) 1 litre 1 per cent. sodium salicylate in normal saline intravenously each day for a week followed by $10 \mathrm{~g}$. to $16 \mathrm{~g}$. daily by mouth, failed to find any advantage in intravenous therapy. In their hands even the largest doses did not prevent the onset of heart lesions or abate the severity of lesions already established, with the possible exception of pericarditis. Harris (1947) likewise failed to find that massive doses of salicylates ( $13 \mathrm{~g}$. to $19 \cdot 5 \mathrm{~g}$. daily) in any way benefited patients with active rheumatic carditis. It would appear that as yet there is no proven advantage in modifying the traditional routine of allowing the relief of pains and swellings in the joints to be the criterion of adequate dosage, the patient being expected to submit to the discomforts of mild salicylism, but not to the major risks of intoxication or intolerance.

Substitutes for Sodium Salicylate.-Hypersusceptibility and idiosyncrasy sometimes interfere with the administration of sodium salicylate. Related compounds can then be given, such as acetyl-salicylic acid, salicin, or the carbonate of ethyl salicylate (Sal-ethyl Carbonate), a nonirritant tasteless powder of low solubility (dose: $0.3 \mathrm{~g}$. to $1 \mathrm{~g}$. at intervals of two to three hours).

Acetyl-Salicylic Acid.-Although acetyl-salicylic acid contains a lower percentage of the salicylate radicle than sodium salicylate does, its anti-rheumatic getivity is about three times as great as that of the parent salt and its toxicity is even less than might have been inferred from its salicylate content. The risks of producing toxic symptoms with clinically effective doses are therefore less. Its special disadvantages arise from idiosyncrasy and gastric irritation. The usual expressions of the former are urticaria, oedema, and a very resistant form of asthma, which preclude further use of the drug. Gastric irritation can be prevented to a large extent by dissolving the compound in a solution of potassium citrate and so reducing the contact-concentration at the mucosal surface.

The sodium, lithium, and calcium salts are soluble and in solution are better tolerated than the acid itself, but they too are irritant if swallowed in tablet form. In aqueous solution they quickly decompose, and under ordinary pharmaceutical storage conditions they break down slowly even in their solid form to mixtures of the salts and free acids of salicylic, acetic, and acetyl-salicylic radicles, which are far more irritant than acetyl-salicylic acid itself. The stability of the calcium salt can be increased by incorporating with it a small proportion of calcium chloride. Calcium acetyl-salicylate stabilized in this way (Mutch, 1934) can be kept for several weeks in its solid form, but not in aqueous solution. Even acetyl-salicylic acid decomposes slowly in its solid form, especially if atmospheric moisture is not carefully excluded, and it should be used whilst still fresh from the manufacturer's plant. If when a bottle of tablets is opened an odour of acetic acid is detected, the contents should be viewed with suspicion. Perhaps the safest method is to use the simple acetyl-salicylic acid dissolved in an excess of sodium bicarbonate solution. All acids present are then converted into innocuous sodium salts and the excess of alkali, by neutralizing the gastric juice, hinders the release of the free acids in the stomach. Such solutions, however, cannot be kept and must be prepared freshly every day.

p-Aminobenzoic Acid.-This substance increases the clinical effect of salicylates and in heavy dosage ( $3 \mathrm{~g}$. to $5 \mathrm{~g}$. two- to three-hourly) has some direct influence on the joint manifestations of rheumatic fever (Rosenblum and Fraser, 1947). Its chief action, however, is to diminish the rate of salicylate excretion by the kidneys and so raise the salicylate $N$ level in the blood (Dry and others, 1946 ; Bélisle, N 1948). For this purpose $2 \mathrm{~g}$. are given two-hourly. It is absorbed and excreted rapidly but, since its chief anti-rheumatic action is exerted indirectly by a raising of the plasma salicyl titre, it is unlikely to $\stackrel{?}{?}$ prove of much value in diminishing the severity of $D$ toxic manifestations occurring during intensive $\vec{O}$ salicylate therapy or caused by hypersusceptibility. $\mathbb{D}$

Cinchophen.-Introduced into clinical use in $\mathbb{D}$ 1908 , cinchophen had already been synthesized at 
a much earlier date in 1887 , and it shares with the so-called coal-tar antipyretics the distinction of being one of the earliest gifts of organic chemistry to therapeutics. Its effect on the rheumatic fever syndrome closely parallels that of salicylates. Even its dosage is similar, at $0.3 \mathrm{~g}$. to $1 \mathrm{~g}$. every few hours, but it does not attain a peak concentration in the blood quite so quickly and doses can be spaced at threeor four-hourly intervals. It may irritate the stomach, and has been known on rare occasions to produce angioneurotic oedema and symptoms resembling salicylism, but patients intolerant to sodium salicylate can usually take it without distress. It should be reserved for cases of extreme salicylate idiosyncrasy because its use is not entirely free from danger. It has long been known that it may cause a very fatal form of hepatitis, the incidence of which is not determined by the magnitude of the dose, the length of the course already taken, or any previous use of the drug. It remains unpredictable, and predisposition cannot be ascertained by any known test. During the period 1925 to 1936 a yearly average of about twenty cases of this type were reported in America, where the estimated annual consumption of the drug was at one time 90,000 lb. (White, 1931). The incidence was therefore about one case per 4,500 lb. consumed, and the death rate approximately one per $9,000 \mathrm{lb}$. From an analysis of the cases reported in the literature from 1913 to 1933, Snyder and others (1935) took an even less serious view of the risks and concluded that one death was attributable for every 17 million doses of $7 \frac{1}{2} \mathrm{gr}$. The danger attaching to its use in any individual is far less than any known surgical risk or that involved in chrysotherapy, and it can legitimately be employed when serious matters of life and health are at stake. It had been hoped that related compounds would be free from the stigma, but hepatitis has been reported after the use of the methyl ester (Novatophan), the allyl ester (Atoquinol), and neo-cinchophen, in which a methyl group is added to one of the benzene rings.

\footnotetext{
Amidopyrine.-The pain, pyrexia, and joint swellings of rheumatic fever respond to this drug also. The dose required $(0.3 \mathrm{~g}$. to $0.6 \mathrm{~g}$. four-hourly) is comparable with that of sodium salicylate. On the rare occasions on which it is employed, it is customary to reduce the dose to $5 \mathrm{~g}$. daily after the first twenty-four hours. Unlike the drugs already mentioned it does not irritate the stemach, but it has the grave disadvantage of occasionally causing agranulocytosis, from which deaths have occurred. Quantitatively the risk involved is far less than the risk of inducing hepatitis with cinchophen. Dameshek and Colmes (1936) showed that after incubation with a susceptible patient's blood, as small a dose as $10 \mathrm{mg}$. of amidopyrine injected intradermally into
}

the same patient would cause an abrupt and severe leucopenia, but no clinically applicable test for predisposition has so far been devised and its occurrence remains unpredictable.

Sulphonamides.-Salazopyrin, a compound of sulphapyridine and salicylic acid, has recently been used in Norway (Svartz, 1948) in acute and̊ chronic polyarthritis including cases of typical acute rheumatic fever, but without unequivocal success. Simple sulphonamides and penicillin have both proved powerless to give symptomatic relief or to check the course of the disease, but some evidence has been presented that sulphonamides may diminish the relapse rate. Coburn and Moore (1939) found that sulphanilamide given to rheumatic subjects after the onset of an interval attack of acute streptococcal infection of the throat did not protect them from recrudescence of rheumatic fever. Used prophylactically, however, it seemed to diminish the incidence of acute streptococcal throats and so was deemed indirectly to safeguard the users against recurrence of rheumatic trouble. Thomas and France (1939) used sulphanilamide in the same way during the winter months to protect rheumatic heart cases. Stokes (1947), using $0.5 \mathrm{~g}$. to $1.5 \mathrm{~g}$. daily for children, could not find any decrease in the haemolytic-streptococcus-carrier rate and reported a significant rise in the proportion of sulphanilamide-resistant organisms in the throat. Griffith (1947) found that sulphathiazole and sulphadiazine used systematically throughout the year reduced the frequency of acute streptococcal infections of the throat, and surmised that in any given group of people who had already had an attack of rheumatic fever this routine might reduce their liability to further attacks. Clearly there is insufficient evidence on the point to justify the systematic dosing of patients with drugs possessing such harmful potentialities.

\section{Gout}

The intrinsic nature of this disorder being still obscure, treatment remains empirical and intuitive.

Acute Gout.-Colchicum, in use since the sixteenth century, is still employed for the acute attack. Most patients obtain dramatic relief although some fail entirely to respond. The active agent is the alkaloid colchicine, and medication can be carried out either with colchicine, $0.5 \mathrm{mg}$., or vinum colchici, $1 \mathrm{ml}$. every two or three hours for four or five doses and then at somewhat longer intervals until relief is obtained or nausea, diarrhoea, or other toxic symptoms manifest themselves. Opium can be used judiciously to counteract excessive looseness 
of the bowels, but it is undesirable to induce a state of constipation. Colchicine is cumulative and very poisonous. A total intake of $8 \mathrm{mg}$. should not be exceeded lightly. With overdosage, colic, haematuria, oliguria, and, later, ascending paralysis of the nerve stem may occur. Its action is curiously specific and no relief is afforded to other types of pain or inflammation. It does not affect the excretion of uric acid or the concentration of urates in the blood. Sodium salicylate and acetylsalicylic acid are often used in conjunction with colchicine and for patients who fail to respond to it. They lessen the pain and inflammation around the joints and have the additional possible advantage of increasing the urinary output of uric acid and lowering its concentration in the blood. This result used to be acclaimed as conferring great benefit on the gouty patient, but it is now realized that the inference may not be justified, the old concept of an attack of gout as representing the deposit of biurate crystals from a supersaturated solution being no longer held adequate to explain the phenomena.

Cinchophen can also be used to relieve the pain, $0.5 \mathrm{~g}$. every two hours for six or more doses.

Chronic Gout.-In this condition colchicine fails to give either relief or protection from recurrent outbreaks, and the drugs in widest use are the cinchophens and salicylates. Both groups relieve the pain of the gouty joint just as effectively as that of rheumatic fever, and both increase the excretion of uric acid whilst lowering its titre in the blood. In this respect cinchophen is the more effective and appears to act by lowering the renal threshold to urates. The modifications in purine metabolism and elimination induced by salicylates have not been so clearly analysed. In the absence of disease in the liver, kidney, and blood vessels, cinchophen can be taken for three or four days in each week in doses of $0.5 \mathrm{~g}$. to $1.5 \mathrm{~g}$. daily until the concentration of urates in the blood becomes normal. This routine has often been kept up for many consecutive months or even years without disaster. Cinchophen is irritant and has been used experimentally to produce gastric ulceration. Similar lesions have been attributed to its use in man (Bloch and Rosenberg, 1934 ; MacBryde, 1940). Sodium bicarbonate can be given to afford some protection to the stomach and to supplement the citrates, acetates, and bicarbonates of sodium, potassium, and lithium commonly given to render the urine aline and keep the extra urates in solution. Butrates are less soluble than the more acidic quadriurates, but none the less urates dissolve more freely in an alkaline urine than in an acid one provided that the alkalinity is not due to the presence of free ammonia. Lysidine, piperazine, hexamine, and thyminic acid have been used traditionally for the same purpose and in spite of much adverse criticism are still greatly in vogue, especially in France. Although vagaries of urate excretion in gout have received so much attention, it must be confessed that cinchophen may give clinical relief without reducing the concentration of urates in the blood and that it may reduce these urates satisfactorily. without controlling the clinical condition. Nevertheless, the great relief which it usually gives to the sufferer from chronic gout is acknowledged everywhere.

As an alternative, generous doses of sodium salicylate or acetyl-salicylic acid can be used, $7 \mathrm{~g}$. daily of the former or $4 \mathrm{~g}$. of the latter, together with protective alkalis. A fall in the urate content of the blood usually follows, but the value rises again when medication comes to an end. To secure results of sufficient permanency the course of treatment should be kept up for three or four weeks.

\section{The Rheumatoid Group}

Many nostrums have been employed in these conditions, but first consideration must be given to those methods which are based on modern concepts of pathogenesis. They are designed to protect the joints from noxious substances of microbic and other origins present in the blood and to promote the healthy activity of all vital functions depressed by abnormal circumstances of the patient's habits and environment; the impairment of his locomotor powers and his confinement to chair, bed, house, or clinic. There are also putative chemotherapeutic agents for the destruction of hypothetical causal organisms. Experience has shown that this considerable equipment can be deployed greatly to the advantage of most patients if discrimination is exercised in selecting the remedial units and in applying them in their appropriate contexts and sequences. Although the primary cause of rheumatoid arthritis remains obscure, much is known about those perpetuating factors which determine the chronicity of the local inflammatory process and the rate of structural disintegration. In the case of a tubercular joint the chief perpetuating factors are movement and mechanical stress. Provided that the general level of health is maintained and the primary focus is not one of advancing type, the arthritic lesion responds satisfactorily when the joint is immobilized and its internal surfaces freed from compression. The rheumatic joint differs from the tubercular in that it appears to be much more vulnerable to abnormal blood constituents which provoke inflammatory 
reactions of varying intensity. The nature of these substances and their modes of action remain matters for enquiry. They may be antigens initiating intracellular antibody reactions or other bacterial products exciting Arthus' phenomena or substances of hitherto unknown type. They are not necessarily related directly to the elusive primary cause. For example, the eating of certain foods or the drinking of particular wines may be followed by strong inflammatory responses in typical rheumatoid joints.

The septic focus has long been held to be an important generating point of such provocatives and little success can be expected from medicinal treatment unless all surface areas of gross infection have been effectively cleansed by dental and surgical procedure. Attention can then be focused on the digestive tract, where provocatives might gain access to the blood from inflamed organs, for example the appendix or gall bladder, from polypi and other tumours, from microbic infestation of the mucosa, and from the bowel contents themselves. The last group is the one with which the present discussion is concerned. Arthus has shown that his reactions can be excited by combinations of extracts from widely dissimilar organisms. Thus the local injection of the filtrate from one bacterial culture followed at a correct interval of time by the intravenous injection of the filtrate from an entirely different species of bacterium may lead to an intense local disturbance at the first injection site. It does not seem unlikely, therefore, that reactions might be produced in a given rheumatoid joint by different provocatives on different occasions. Consequently all suspected areas should be purified.

The study of allergy and of the formation of antibodies and precipitins after the ingestion of foreign proteins and vaccines has revealed that molecules of sufficient complexity to retain antigenic properties can pass through the intact lining of the bowel. The normal products of digestion appear to be innocuous, except to those subject to food allergy. The chief responsibility for the production of pathogenic compounds must be placed on the activity of micro-organisms. All deviations of digestion should, therefore, be corrected and opportunities reduced for the production and absorption of antigens and other provocative compounds thrown off by the intestinal flora or arising from the action of digestive enzymes operating in a bacterially contaminated medium. In the small intestine zymolysis should proceed under aseptic conditions, but in many circumstances bacteria reach the area from inflamed zones above, whilst others may ascend from below, and a third quota be shed from the adjacent mucosa whenever it is infected. The large intestine always contains bacteria of many races which have established what may indeed be a helpful symbiosis, but microbic activity of abnormal form and degree will develop if an excess of nutrient matter is allowed to mix with the faeces. This occurs whenever diet is excessive or unsuitable or the power of the digestive enzymes is impaired or the processes of absorption are faulty. The diet must be simple and correctly balanced. Evacuation must be satisfactory. These are the primary essentials of alimentary therapeutics, but cannot be dealt with in detail here. Colonic lavage often relieves rheumatic pain-in the severely constipated and can be used to introduce potassium permanganate, lactic acid, or other substances to cleanse such remnants as cannot be washed away. Ox bile will reduce the surface tension of the lavage fluid and facilitate its penetration of recesses, ledges, and diverticula.

Digestants.-Acids and antacids have their uses but there are more direct methods of assisting the digestive juices. Many pharmaceutical enzyme preparations are too weak to make any material difference to gastro-intestinal chemistry in the doses which are prescribed. Two, however, appear to satisfy the quantitative requirements.

Takadiastase, produced by the action of aspergillus oryzae on moist rice, is used to convert starch into sugar in the manufacture of saké and some forms of whisky. Good samples are six times as powerful as malt-diastase - and outclass even diastase vera. Most diastatic ferments are destroyed by the acid in the stomach, but takadiastase passes through without impairment. In amylaceous dyspepsia $200 \mathrm{mg}$. or $300 \mathrm{mg}$. doses at meal times produce obvious clinical improvement. When an excess of carbohydrate is retained in the colon, the streptococcal elements in the flora gain dominance over the coliform organisms. If stagnation is profound, they in their turn succumb to the advancing acidity generated by the acidophilus group, but more usually the process continues only as far as the streptococcal stage. It can be argued that a flora of this type is harmful to the rheumatic subject, and indeed it is often associated with an increase in rheumatic pain. It can be corrected by simplifying and reducing the starchy foods in the diet, treating the constipation, and giving takadiastase to augment the natural diastase of the pancreatic juice.

Erepsin.-The proteolytic enzymes secreted b the intestinal mucosa are collectively called erepsin and complete the proteolysis initiated by the secretions of the pancreas and stomach. The work 
of Renshaw (1947) encourages the belief that erepsin can be made to play a useful part in antirheumatic therapy. Its action is to speed the later phases of protein digestion and so reduce the amount and complexity of the protein remnants which reach the infected areas of the lower bowel. It is available as Benecol, an extract of intestinal mucosa in the form of tablets specially coated to prevent inactivation by the gastric juice. Three to nine tablets are taken daily between meals.

Bile Salts.-Although devoid of enzyme activity, bile salts are essential to the digestion of fats. They increase the flow of bile, activate the lipase of pancreatic juice, confer water solubility on fatty compounds, and promote the formation of superfine emulsions essential for full lipolysis and absorption. They can be prescribed as sodium tauro-glycocholate B.P.C. in $250 \mathrm{mg}$. doses between meals. Being hygroscopic, soluble, and in high concentrations irritant to the gullet, they must be given a suitable protective coating. They effectively control the symptoms of minor fat intolerance and true biliousness. A small marginal dose to supplement the bile salts produced naturally in the liver is all that is needed in most cases, and since they are absorbed and re-excreted in the bile over and over again they need not be given every day. Three or four doses weekly usually suffice. Alternatively dehydrocholic acid and sodium desoxycholate can be used for the same purpose as therapeutic equivalents, although the former lacks the valuable direct action on lipolysis possessed by the natural bile salts.

Intestinal Antiseptics.-The older remedies of this type have long been discredited. Sulphaguanidine, succinyl-sulphathiazole, and phthalyl-sulphathiazole now enable big reductions to be made in the colonic flora, but their applications in rheumatic diseases are very limited. Their administration is not followed by any obvious change in the condition of the joints, but the general condition of a bedridden patient with toxaemia resulting from grossly dislocated digestion may be temporarily improved. For more continuous use less toxic compounds are required. Those which seem to have proved most satisfactory are the halogen-substituted phenols.

Many have been studied, and germicidal power has been found to increase as more and more halogen atoms are introduced into the ring. Iodine has proved to be rather superior to bromine, and the bromine compounds are a little more active than those containing chlorine. Halogen derivatives of the higher homologues of phenol are more potent still, those containing the n-amyl group being strongest. The toxicity of most of them is low (Klarmann and others, 1934). The minimum lethal dose of p-chlorophenol injected subcutaneously into mice was estimated as $0.6 \mathrm{mg}$. per g. of body weight (Meleney and others, 1946).
On the basis of body weight equivalence this corresponds to a $40 \mathrm{~g}$. dose for an average man. A juster assessment was made by Gersdorff and Smith (1940), who compared the toxicities of o-, m- and p-chlorophenol using phenol as a control. In each case the toxicity of the chlorine compound slightly exceeded that of phenol. Pentachlorophenol is an exception, and although not very harmful in single doses, after repeated administration it acts as a cumulative poison. Most of the series dissolve freely in lipoid solvents but all except the simplest members are relatively insoluble in water ; thus, p-chlorometaxylenol B.P., with a Riedel Walker coefficient of 36 , dissolves at 1 in 3,000, 2.4.dichlorophenol, R.W. Coef. $13 \cdot 3$, is soluble 1 in 250 , whilst o-chlorophenol is soluble 1 in 140 but its R.W. Coef. is only $2 \cdot 3$. The irritant and local analgesic properties of these compounds must also be taken into account.

Some of those in medical use are: parachlorometacresol B.P. and parachlorometaxylenol as external disinfectants. Tribromophenol, almost insoluble in water, is used in pill form (30 mg. to $120 \mathrm{mg}$.) as an intestinal antiseptic, p-chlorophenol $(0.25$ per cent.) for wounds, and the mixture known as T.C.P. (principally 2.4.dichlorophenol together with o- and p-chlorophenol) for external and internal purposes. In the last preparation a useful balance has been struck between solubility, potency, and irritancy and a 0.6 per cent. solution of mixed chlorinated phenols has been provided with germicidal power approximately equivalent to 10 per cent. aqueous phenol. After moderate dilution it is well tolerated by mouth and can be taken regularly for many months without any adverse effects.

Phenolic preparations not containing halogen substituents also have been used internally, for example, amyl-metacresol, R. W. Coef. 250 but almost insoluble in water. It is given in capsules containing $150 \mathrm{mg}$. dissolved in oil. Dimol " 43 ", R.W. Coef. 43 , is a mixture of alkyl substituted phenols and methoxyphenols employed for the same purpose. These substances, potent but insoluble, probably exert a little antibacterial action at all levels of the alimentary canal but do not greatly change either the faecal flora or the essential rheumatic syndrome. An aqueous solution of greater molecular strength of the simpler chlorinated phenols is far more effective clinically even though the constituent substances are less powerful germicides. Their absorption is rapid, so that their activity is probably expended in the small intestine. Even pentachlorophenol quickly finds its way into the circulation and Machle and others (1943) found peak values of $10 \mathrm{mg}$. per $100 \mathrm{ml}$. in rabbits' blood three hours after large but sublethal doses had been given by mouth. If taken some hours after the last meal of the day, solutions of mono- and dichlorophenols probably maintain bacteriostatic concentrations in the small intestine for a time and so protect the processes of normal enzymic digestion from chemical distortion by collateral microbic action. The diminution 
in rheumatic pain which can follow such medication is often so striking as to suggest that some additional mechanism may be at work, such as the denaturing of abnormal breakdown products with harmful antigenic properties by their linkage with the administered drug.

Mineral Adsorbents. - If provocative substances entering or formed in the digestive tract could be destroyed, precipitated, or removed from aqueous solution in some other way, they would be prevented from reaching the circulation. Kaolin and other actively adsorbent materials are given with this objective in view. When more than one substance is taken up by an adsorbent, they may be modified by mutual interaction under the catalytic conditions obtaining at the adsorbing surface. In their original or modified forms they may be held firmly and excreted in the faeces, or in the new chemical environments encountered at lower levels they may be eluted or displaced by other compounds and so returned to solution. Whether after these vicissitudes they now reach the blood stream or not will be determined by the absorptive powers of the mucosa at the new alimentary level. In the face of so many factors the only method of assessing the practical value of mineral adsorbents in any particular disease is that of clinical trial. The two which have appeared to give most relief in rheumatic disorders are kaolin and acid-resistant alumina, but silica-gel, bentonite, and other strongly adsorbent materials might be tried.

Kaolin should be as pure as possible, for example kaolinum leve B.P., and since it tends to cause constipation it should be combined with an aperient. A useful combination is kaolin $10 \mathrm{~g}$. in $250 \mathrm{ml}$. 0.5 per cent. aqueous sodium bicarbonate containing a sufficiency of Glauber's salts (magnesium sulphate is less suitable for this purpose) about half an hour before breakfast. The lining of the stomach and small intestine is thus washed over with the adsorbent whose residual activity is expended in the colon. A similar dose given at bed time, with a vegetable aperient substituted for the saline, will exert its action amongst the still digesting elements of the meals of the current day. Acid-resistant alumina (Mutch, 1946) should be selected for its adsorption potency and its freedom from antacid activity. If the usual acid-reactive gels used in the treatment of peptic ulceration are employed they will interfere with gastric digestion by lowering the acidity in the stomach and by destroying the pepsin (Schiffrin and Komarov, 1941). Alumina can be given as a supplement to kaolin since it adsorbs an entirely different range of compounds. Although somewhat catholic in its affinities, preferentially it takes up substances with anionic properties whilst kaolin selects the kationic.

Upper Alimentary Lubrication.-Many of the discomforts of dyspepsia (heartburn, eructations, repetitions, anorexia, nausea, vomiting and distension) resemble in minor form the syndrome of obstruction and can often be corrected by lubrication. For this purpose a 25 per cent. to 30 per cent. $\mathrm{O} / \mathrm{W}$ emulsion of well homogenized heavy mineral oil answers well, since it mixes evenly with whatever fluids it may encounter and so sustains an even action. To exert the greatest effect on the pylorus, duodenum, and ileum, it should be given about twenty minutes before each meal so that it can find its way to all levels undiluted by the food. An even better clinical effect is produced if one of the adsorbents. just discussed is suitably suspended in the continuous aqueous phase of the emulsion. Such preprandial dressing by adsorbent and lubricant in readily dispersible form is a measure of wide applicability for rheumatoid patients who are confined to bed and for others with persistent symptoms of the simpler forms of dyspepsia.

Before considering more specific measures it can be pointed out that the methods so far discussed for use in arthritic cases are just as useful in the treatment of the commoner forms of non-articular fibrositis. Some patients with the latter complaint are extremely sensitive to events in their alimentary tracts. The gastric delay caused by the persistent use of phenobarbitone is sometimes sufficient to perpetuate rheumatic pains of this type and even to cause relapse in a patient whose pains have previously been controlled.

Septic Foci.-The eradication of the septic focus is chiefly a surgical responsibility, but extensive infection of a chronic kind often persists in the throat, nose, and sinuses after all operative advantages have been taken. Bacterial insemination of the alimentary tract from such areas continues and can only be diminished by non-surgical means. Perhaps the best method of dealing directly with these infected areas is to use nebulized mists of penicillin and sulphonamide. Hand nebulizers are inadequate. To disperse a sufficiency of drug in an appropriately fine form the higher power and capacity of apparatus operated by oxygen pressure or by an electrically driven compressor are needed. It has been shown (Mutch, 1944 ; Mutch and Rewell, 1945) that sulphonamide and penicillin can be administered and absorbed in this form and concentrations sufficient for chemotherapeutic purposes established even in the blood. Wilson and others (1945) demonstrated the curative action of such mists in experimental pneumonia, and later clinical trials both here and in America have further explored the 
practical applications and limitations of the method. The phial is charged daily with 200,000 units of white crystalline penicillin dissolved in $2 \mathrm{ml}$ : of sterilized water, and $2 \mathrm{ml}$. of a strong neutral solution of the selected sulphonamide are added. Soluthiazole, available as a 45 per cent. aqueous solution, is the most suitable since it dominates the same wide bacterial range as sulphathiazole, is extremely soluble in water, and forms a neutral solution. Used at half strength, as in the mixture suggested, it does not irritate the respiratory mucosa. Its combination with penicillin prevents the increase in the density of the Gram-negative flora which follows the use of penicillin alone and greatly reduces the incidence of stomatitis. Three sessions are arranged daily, one third of the solution being nebulized and inhaled on each occasion. Similar sessions are held on three consecutive days, and further series given after an interval varying with the severity of the condition from a few weeks to a few months. Timing of the various administrations can be modified indefinitely to suit the needs of any particular case.

Specifics.-Many of the older drugs have fallen into considerable disuse in spite of the hopeful experiences often recorded with them. Such amongst others are iodine, sulphur, thiosinamin, o-iodoxybenzoates, bee venom, and short-life radioactive derivatives of thorium and radium. It is proposed to leave their reputations in other hands and proceed to newer matters. Penicillin and sulphonamide have failed to give specific relief, although they are of great service in the treatment of septic foci, but gold still grows in popularity.

Gold.-About $1 \mathrm{mg}$. of gold is taken daily with the food and eliminated in the faeces (Berg, 1928). Its administration for rheumatic disease was first proposed by Feldt (1926), and clinical trials were made by Forestier (1929) and Umber (1929), with intravenous injections of gold sodium thiosulphate. During the succeeding two decades it has firmly established. itself as useful therapeutically. A number of organic compounds, most of which are proprietary, have been devised. Seven or eight are mentioned in Martindale and in the U.S. Dispensatory. One of the most popular to-day is sodium aurothiomalate, which can be injected intramuscularly either as an aqueous solution or as a suspension in oil. The calcium salt is insoluble. Injected as the sodium'salt, gold quickly reaches the blood, where it is carried in the plasma. The greater part of it is then deposited in the tissues and the small surplus appears in the urine. Elimination by the kidney attains a maximum on the actual day of injection. Gold finds its way into the synovial and cerebrospinal fluids, but at lower concentrations than those in the blood where a titre of $0.8 \mathrm{mg}$. per $100 \mathrm{ml}$. may be established during a standard course of therapy. Gold is released slowly from its storage depots and may continue to be excreted for many months or even a year after the conclusion of a series of injections. Insoluble compounds such as gold sulphide behave differently. They are phagocytosed and removed from the injection site so slowly that the plasma titre remains persistently low. The greater part is deposited in the liver in an inert form. The insoluble salts are less toxic than the soluble ones, but they are also less effective therapeutically.

Mode of Action.-Gold is distributed selectively in the reticulo-endothelial system including the corresponding cells at sites of chronic inflammation (Koppenhöfer, 1935) and it has been suggested that it produces its therapeutic effects by stimulating phagocytes and other defence mechanisms, but evidence is steadily accumulating in favour of the view that its action is a truly chemotherapeutic one leading more directly to the death of invading organisms. Most of the work has been done on experimental arthritis produced by streptococci and by pleuropneumonia types of organism. Schiemann and Feldt (1926) and Feldt (1926) found that gold was curative for streptococcal infections in mice. Hartung and Cotter (1941) showed in man that the bacteriostatic power of the serum for haemolytic streptococci was raised during gold treatment and that a quantitative relationship existed between the dose of gold and the degree to which the bacteriostatic power was increased. Rothbard and others (1941) found that gold would protect an infected rat from the development of joint lesions although it was not curative if given after the joints had become involved.

These results are no more than suggestive of a possible chemotherapeutic action in man, but those obtained with infections of pleuropneumonic type have been far more encouraging. Although search for the presence of such organisms in rheumatoid arthritis has so far failed, in rats they produce chronic inflammatory lesions in the joints resembling in many ways those of the rheumatoid subject. Findlay and others (1940) found that by means of gold the onset of arthritis in animals inoculated with pleuropneumonia-like organisms could be prevented. Heilman (1940) observed that sodium aurothiomalate would protect mice from otherwise lethal doses of the associated streptobacillus moniliformis, a finding confirmed by Brown and Nunemaker (1942). Sabin and Warren (1941) noted some dose-response variation for the curative action of suitable gold compounds in the chronic proliferative arthritis of rodents. With full doses given during the early stages of the disease the cure rate was almost 100 per cent. With smaller doses and when treatment was started later in the disease, the cure rate was 21 per cent. The spontaneous recovery rate in control groups was 6 per cent. Over 1,000 mice were used in these experiments, which seem to furnish 
a strong case for regarding the action of gold salts in the arthritis of rodents as a chemotherapeutic one and justify a hopeful belief that gold may play an analogous part in rheumatoid arthritis as it occurs in man.

Application.-It is widely agreed that chrysotherapy is only appropriate in arthritis of chronic infective type in its active stage when the blood sedimentation rate is high. The risk of serious toxic manifestations is greatly reduced if patients with kidney, liver, skin, and cardiovascular disease are excluded and the more conservative modern scales of dosage are employed, for example intramuscular sodium aurothiomalate individual doses scaled from $0.01 \mathrm{~g}$. to $0.05 \mathrm{~g}$. at intervals of a week and continued to a maximum total of $0.5 \mathrm{~g}$. After a rest period of two or three months to provide opportunities for elimination the injections can be continued at similar rates, but even smaller doses have been advocated by experienced workers in this field.

There are two common modes of therapeutic response: the one a long and steady improvement in the condition of the joints paralleled by a fall in the sedimentation rate and disappearance of all remnants of pyrexia, and the other a painful reaction in the affected joints and possibly a little fever following closely upon each injection. If these latter are severe they. necessitate a gentler graduation of the dose and a lengthening of the inter-injection periods.

It is important that a proper background should be provided for chrysotherapy by treating infected foci and the alimentary tract thoroughly before the first injection is given. If this is done conscientiously many patients will recover without requiring gold, but in certain cases active intoxication persists until gold has been administered. When toxaemia and variations in the severity of local inflammation continue after every effort has been made to cleanse the mucosal surfaces and associated zones of focal infection, it would appear either that a specific microbic infection has been established in the joints or that the joint tissues have become so sensitized as to react violently to traces of antigen and other provocatives which would have been well tolerated by other patients. In accordance with these views it could be conceived that gold affords relief either by overcoming the microbic elements in the joint or by protecting the sensitized tissues from excessive reactions, possibly by combining with such antibodies and other receptor substances sorbed on to these tissues as are capable of reacting with blood-borne provocatives.

One of the most recent clinical summaries is that of Sundelin (1948) on 1,904 cases of rheumatoid arthritis treated with 2,817 courses of gold-principally gold thiosulphate-averaging $0.83 \mathrm{~g}$. of the element per course. He reports rapid benefit in 90 per of his cases (but the later results were not assessed), a 4.5 per cent. incidence of severe complications, and a death rate of 0.36 per cent. These figures closely resemble those of Nyst röm (1948), who used one of the varieties of Solganal in 620 cases, giving an average of about $0.9 \mathrm{~g}$. per course. The severe complication rate was 6.8 per cent. and the death rate 0.32 per cent. There were many instances of moderate leucopenia, eosinophilia, thrombocytopenia, anaemia, and albuminuria, but they were classified as minor derangements and were not allowed to interfere with the course of injections.

Antidotes.-The older treatment of toxic complications by withdrawal of the drug and the adminis tration of thiosulphate of sodium, magnesium, or calcium has been strongly reinforced by the recent introduction of BAL, a dithiol containing protective sulphydryl groups developed as an antidote to arsenical war gases. Good results have followed its employment in dermatitis, thrombocytopenic purpura, and granulocytopenia produced by gold (Peters and others, 1947; Slot and McDonald, 1947; Cohen and others, 1947; Ragan and Boots, 1947; Simpson, 1948; Macleod, 1948). The gold attaches itself to the sulphur atoms of the BAL radicle to form a non-toxic compound. It is contra-indicated by the presence of liver damage, but kidney lesions do not preclude its use. It is supplied as a 5 per cent. solution in oil for intramuscular injection. $2 \mathrm{ml}$. are given four-hourly for four doses on the first day. Two doses are then given each day and later reduced to one, over a period of six to ten days, but larger doses have been used and the treatment kept up for several weeks.

The toxicity of gold, no less than the striking successes recorded of its use, have led to trials with other metals particularly with bismuth, copper, and aluminium, in the hope that equal benefits might be obtained at smaller risk. Aluminium administered as the acetate has so far failed to help. Bismuth and copper merit further trial.

Bismuth.-Bismuth compounds are comparatively non-toxic and rarely cause fatal complications. The clinical records so far published are promising but far more data are needed before the curative action of these compounds in arthritis can be admitted. They are treponemostatic in vitro and deprive the syphilis organism of its infective powers. By analogy it is hoped that they may act in a similarly direct manner on the presumed infective agent of rheumatoid arthritis. Many varieties are available for intramuscular injection dissolved or suspended in water and water-miscible solvents or in oil. In most compounds the bismuth plays a basic part, but in Iodobismitol (sodium iodobismuthite) and Sobisminol 
(sodium bismuthate) the element is incorporated in the acid racticle. The last-mentioned substance has the distinction of being absorbed in effectively therapeutic quantities when administered by mouth (Hanzlik and others, 1937, 1938: Sollmann and others, 1938). The posology in rheumatic conditions is still in an experk mental stage. The present recommendations are that individual doses should be about one-fifth of those used in syphilis with a month's interval between them at first and a gradual spacing out until three months may intervene between the eleventh dose and the final twelfth. Some of the water-soluble forms are precipitated locally after injection. They, like those which are initially insoluble, are slowly converted into tissue-soluble forms and carried away in solution. The thioglycollate is exceptional in that it is soluble not merely in water but in tissue fluids too, so that its diffusion from the injection site is accomplished very rapidly. Concentrations in the blood and the urinary excretion rate do not reach peak values untilthe fourth or fifth day after an injection of the salicylate but are maximal on the actual day of injection when the thioglycollate or iodobismuthite are used. As a guide to further trials it can be pointed out that oily suspensions of insoluble bismuth salicylate B.P. are absorbed slowly and exert a constant sustained action, whilst the water-soluble compounds Thiobismol (sodium bismuth thioglycollate), Iodobismitol, and Sobisminol act quickly and are suited to therapeutic pulsations of higher frequency. The normal serum-titre is about $130 \mu$ g. per $100 \mathrm{ml}$. (Brendstrup, 1948).

Copper.-The physiological importance of copper is well known. The element is present in food and the usual daily turnover is 2 to $2 \cdot 5 \mathrm{mg}$. (Tompsett, 1934): The possible chemotherapeutic action of its organic compounds was investigated by Dixon and Hoyle (1921), but the ethylene thiocarbonate which they used did not seem to be helpful in animal tuberculosis. Fenz (1941) introduced them for the treatment of rheumatic conditions. Forestier and Certonciny $(1946,1947)$ and Forestier and others (1948) carried out more extensive trials using the sodium salt of cupro-allylthioureameta-benzoic acid (Cupralène, Cuprelone) intravenously and cupro-oxyquinoline-sulphonate of methylamine for intramuscular injection. Even the latter compound is irritant and is given with procaine. The diethylamine (Dicuprène) is also used. The number of cases reported is too small for statistical treatment but on the whole such clinical improvement as there may have been was not of a greater order than that following the use of gold. $5 \mathrm{ml}$. of a 10 per cent. solution of the oxyquinoline compound ( $=30 \mathrm{mg}$. $\mathrm{Cu}$ ) were given two or three times, a week in six-week courses with gaps of four to eight weeks. Toxic manifestations were few and not serious. Recently the old controversy as to the possible production of hepatic cirrhosis by copper has been raised again by Forbes (1947). The original suggestion came from Mallory (1926), who attributed the common type of hepatic cirrhosis known as gindrinker's liver to copper contaminants in the spirits rather than to the alcohol. The evidence of later workers was often contradictory, and the case for the original hypothesis was never established. In view, however, of the magnitude of the doses of copper now advocated for therapeutic purposes, the possibility of its giving rise to delayed cirrhosis must be borne in mind.

\section{Remission Factors}

Pregnancy.-It is an old observation that the joint condition of women with rheumatoid arthritis often improves markedly during pregnancy and that relapse in the puerperium may be equally dramatic even before the patient has resumed her household duties. The beneficent influence may be hormonal, but eludes reproduction by hormone therapy. Possibly it depends on other chemical changes in the blood, such as the presence of the histaminolytic agent described by Anrep and others (1947) in plasma during pregnancy. They could not find it in normal blood, and the histaminolytic index " H 1 " fell rapidly during the puerperium, diminishing to half values in twenty-four hours and quarter values after two.days. Such a substance, possibly a histaminase enzyme, could be expected to diminish joint disturbances caused by local histamine-release during antigen-antibody interactions. The earlier work on the subject has been summarized by Ahlmark (1944). Anrep could not raise the H 1 value artificially by daily injections of histamine in either dogs or man. Transfusion with blood from pregnant women has been tried as a therapeutic measure in rheumatoid arthritis (Barsi, 1947), but the results merely reflect those of Appelqvist and Holsti (1947), who used transfusions of ordinary blood. When the case reports are compared it is impossible to discern any special advantage in using pregnancy-blood. Further research is needed before any definite therapeutic advance can be made along these lines.*

Histamine Antagonists.-If any considerable fraction of the joint disturbance in rheumatic diseases is caused by histamine-release, it might be expected that good use could be made of the recently introduced histamine-antagonist drugs. Mayer and Kull (1947) have produced evidence that at least one of these drugs, pyribenzamine, antagonizes hyaluronidase as well as histamine, whilst Fischel (1947) failed to find that it modified the Arthus reaction. The clinical reports of Benadryl in subacute arthritic cases in the United States Naval Reports (1948) were non-committal. My own limited experience is that Antistin sometimes gives relief from pain comparable with that of acetylsalicylic acid in osteo-arthritis and old-standing rheumatoid arthritis. Some allergic phenomena are more definitely influenced than others by these drugs. The differentiation in effect may depend

\footnotetext{
* See also article by Hench and others at p. 97 of this issue.
} 
partly upon whether the histamine disturbance is produced intracellularly as is presumed to be the case in asthma, or extracellularly as in simple flare, but further ingenuity is needed to explain the inability of Neoantergan to antagonize the action of intravenously injected histamine on gastric secretion and the failure of pyribenzamine to control the skin response to intradermal tuberculin in tubercular subjects (Fischel, 1947).

The older Histamine-antagonists, Benadryl, Antergan, Antistin, and pyribenzamine are now supported by many others : for example, Anthallan, Decapryn, Linadryl, Anthisan or Neoantergan, Neohetramine, Chlorothen, and Bromothen, and have recently been supplemented by a new chemical series based on pyridindene, for example Thephorin, and thirdly by derivatives of phenthiazine in the form of R.P. 3277 (Phenergan), and Pyrrolate. Others will doubtless quickly follow, evoking various patterns of therapeutic response. It would not seem unreasonable, therefore, to hope that presently some useful application will be found for them in the treatment of rheumatic disorders.

Jaundice.-It has been noted on several occasions that in cinchophen poisoning in rheumatoid patients the onset of jaundice has been marked by a striking improvement in the condition of the joints. Hench (1938) took the matter further and recorded similar remissions during intercurrent attacks of jaundice from other causes, both obstructive and intrahepatic, although many exceptions occurred. Relapse followed quickly as the jaundice cleared. Therapeutic attempts to give relief with bile salts by mouth, human bile by stomach tube, ox bile by rectum and bilirubin and sodium dehydrocholate intravenously proved useless. Transfusions with jaundice-blood and injections of liver extract were equally disappointing. No means of copying the natural phenomenon has been found, but a promising field remains open for further research.

\section{Local Measures}

Intra-articular Injections.-Disorganized joints often remain painful after toxaemia, as assessed by the sedimentation rate, has passed. This is the condition in which intra-articular injection therapy has principally been applied, although some enthusiasts also use the technique for more actively inflamed joints. Several types of solution have been used, the most popular during the past ten years being an acid solution of procaine adjusted to $\mathrm{pH} 5$ by the addition of lactic acid, acid potassium phosphate, or ascorbic acid (Waugh, 1938 and 1946; Crowe, 1944; Leon, 1948). The object is to provoke a mild inflammatory response with a local leucocytosis in the anticipation that in the aftermath of repair the joint will become more comfortable. Baker and Chayen (1948) confirmed the findings but obtained equally satis- factory results with neutral solutions of procaine in isotonic saline using $10 \mathrm{ml}$. for a hip or knee, $5 \mathrm{ml}$. for the shoulder, and $1 \mathrm{ml}$. for the thumb. They attributed the benefits to the psychological effect of the prompt relief afforded by the procaine and to the lubricant action of the injected fluid. Even alkaline solutions appear to be helpful. Kron (1948) used isotonic sodium bicarbonate ( 1.29 per cent.) and injected $0.5 \mathrm{ml}$. to $2 \mathrm{ml}$. on alternate days for two to four doses.

Liniments.-Experiments in which referred pains have been evoked by the injection of fluid into the interspinous ligaments have shown that the pain can be abolished by the injection of a local anaesthetic into the skin of the area to which the pain is referred. Conversely, positive stimulation of a pleasant kind applied to the same cutaneous areas also reduces the pain; for example, the tingling of aconite, the coolness of menthol, and the warmth of the rubefacients. These means can be variously combined to suit the individual needs of the patients. When there is much skin hyperaesthesia, as in neuritis, the local analgesics must be stressed and the positive stimulants applied with caution. Perhaps the most useful for this purpose are benzyl alcohol and salicyl alcohol (saligenin) as 5 to 10 per cent. solution in a skin-penetrating lipoid solvent such as terpineol. All three substances are mildly stimulant also but their combined effect is reduction of hyperaesthesia. The unwanted stimulant element can be reduced without interfering with the analgesic action by replacing some of the terpineol with alcohol up to 20 per cent. It can be increased by adding mildly stimulant rubefacients such as methyl salicylate and camphor. In the absence of cutaneous tenderness, stimulation can be applied more robustly by means of the stronger official liniments of the Pharmacopoeia, care being taken not to blister the skin or produce a rash. The superficial hyperaemia thus established is accompanied by deep reflex vasodilatation, which it is hoped may exert a healing influence on the damaged joints. The mechanism resembles that of radiant heat therapy, in which deep hyperaemia is produced reflexly in response to the heating of the surface layers of the skin. Many substances when dissolved in lipoid solvents of low surface tension penetrate the skin and reach the blood stream. Amongst those of importance in rheumatic diseases are the esters of salicylic acid, acetyl-salicylic acid, and phenyl-cinchoninic acid, which are all absorbed freely by this route. The amyl ester is generally used in the case of phenyl-cinchoninic acid, and the methyl esters of the other two compounds. They produce a small but useful degree of skin 
stimulation but after absorption do not reach the sites of their various antirheumatic activities any more quickly than they would have done had they been absorbed from the alimentary canal. They do, however, escape the chemical interference and censorship of the liver and the gut.

Muscular Relaxation.-For nocturnal cramps the muscle depressant action of quinine is often useful, but the ideal drug for securing continuous relaxation of muscle spasm in active arthritis has still to be found. Several are on trial. The one in longest use is neostigmin (Prostigmin) although its modus operandi in this connexion is difficult to discern. Its chief action is to inhibit cholinesterase and so increase the effectiveness of acetylcholine released at the myoneural junction on stimulation of the motor nerve. This is believed to be the basis of its utility in myasthenia gravis, and it might be expected to lead to an increase rather than a decrease in the tonus of spastic muscles. It can be given in $15 \mathrm{mg}$. tablets by mouth once or twice a day or $1 \mathrm{mg}$. subcutaneously daily, combined with an adjusted dose of atropine or belladonna to antagonize some of its unwanted effects. Injection is often followed by a short period of diminished pain, but sometimes it appears to aggravate the discomfort. Trommer and Cohen (1944) spoke well of it but later clinical reports have not justified the enthusiasm of earlier users (Lucchesi and Lucchesi, 1945-6, 1946).

More recently introduced drugs, clinically in an experimental stage, are Parpanit, a compound related chemically to pethidine, and Trasentin, an atropine-like drug, used with success in Parkinsonism and experimentally causing marked diminution in muscle tone (Heymans and de Vleeschouwer, 1948). Myanesin, an $\alpha$-glycerol ether devised as a substitute for curare, produces complete muscle relaxation, and if the dose is correctly adjusted there is no interference with respiration (Berger and Bradley, 1946, 1947). Its properties differ in many ways from those of curare, but both drugs exert a strongly depressant action on striated muscle at the myoneural junction. It is absorbed satisfactorily from the stomach and after absorption is quickly metabolized so that its effect is not of any long duration. The transience of its action may restrict its use in protracted medical conditions and its application to the problems of arthritis awaits elaboration.

Amalgesics.-The specific relief afforded by salicylates, colchicum, and cinchophen has already been discussed. There are other drugs with wider fields of effectiveness and special indications. Acetyl-salicylic acid in its many guises is familiar to all. Of the pyrazolon derivatives, amidopyrine has already been mentioned. The other member of the group, phenazone or antipyrine, is not quite so effective but is free from the stigma of causing agranulocytosis. It has been in service since 1884. Acetanilide from aniline and phenacetin (aceto- $\frac{D}{\infty}$ phenetidin) from p-aminophenol are almost as ancient and are approximately equivalent in power. They too have never been known to depress the -7 white cell count dangerously. But these three safe $\frac{C}{0}$ analgesics lack the specificity of amidopyrine in $\bar{\omega}$ acute rheumatic fever. The general public consumes them in considerable amounts. Cases of chronic poisoning are therefore not rare although difficult ${ }^{\mathrm{c}}$ to diagnose since the symptoms resemble those of $\vec{\circ}$ other common conditions. They include anorexia, $\vec{\overrightarrow{ }}$ loss of weight, anaemia, weakness, short windedness, $\stackrel{\omega}{\circ}$ indigestion, and insomnia, whilst the blood changes on which the common tinge of cyanosis depends may be difficult to analyse in the laboratory. Kryofine in (methoxy-aceto-phenetidin), Phenamide (phenocoll $-\overrightarrow{-}$ hydrochloride), and lactyl-p-phenetidin belong to or the phenacetin group whilst Exalgin is an acetanilide 을 derivative. The phenyl semicarbazides form a fourth chemical group, represented by Cryogenine, $\subseteq$ now defined as 1-phenylsemicarbazide (FrCx) and $\overparen{D}$ formerly as 3-semicarbazidobenzamide (Lumière), $\vec{\varphi}$ safe analgesics with therapeutic activity approximat- $\frac{\overrightarrow{ }}{0}$ ing to that of phenacetin. Often, as in the treatment of sciatica, more powerful analgesics are required. Morphia has frequently been used, but tolerance is soon acquired and it is not only causes addiction but may lead to gross alimentary derangement. It is very difficult to cure any form of rheumatism in a persistently constipated patient. Its isomer dihydromorphinone, better known as Dilaudid, does not cause constipation. It is about ten times as powerful as morphine. A useful dose for oral administration is $2.5 \mathrm{mg}$., and the maximum $4 \mathrm{mg}$., which can be repeated with safety up to three times in twenty-four hours. Its narcotic effect is variable but not great. Metopon, another morphine derivative, has recently appeared in America and the reports of its properties suggest that in respect of pain relief, narcosis, and constipating action it occupies an intermediate position between morphine and Dilaudid.

Pethidine (Dolantin, Dolantal, Demerol) belongs to an entirely different chemical class and structurally is related to atropine. It was synthesized by Eisleb and Schaumann (1939), but only became available in England during the later stages of the world war 1939-45. It can be used by mouth for the relief of pain and in $25 \mathrm{mg}$. doses produces definite euphoria but it does not cause narcosis unless larger doses are given. It does not cause constipation, and its additional action of allaying hypertonus in plain muscle may even correct constipation of the spastic type. Work done on various 
German formulae has given us amidone, known variously as Physeptone, Miadone, and Methadon. Dolophine is probably identical, although the structural formula given does not always agree exactly with that attributed to amidone. The average analgesic dose for oral use is $10 \mathrm{mg}$., but $5 \mathrm{mg}$. are often sufficient. Scott and his co-workers (1947) reported its use in joint conditions and found that although it usually controlled osseous pains it was not so consistently effective against pains of articular origin. For the pain arising from ischaemic muscle, Hewer and Keele (1947) found it to be as effective as morphine and far more effective than pethidine. It may cause a little nausea and constipation, but not of the same degree as that following the use of morphine. Euphoria is rarely noticed. Nevertheless, both amidone and pethidine have been placed under the control of the D.D.A. regulations after very careful official consideration of their qualities. The most recent of the heptanone series to be tried clinically is " C.B.11" (Heptalgin). Wilson and Hunter (1948) demonstrated that it could be used to relieve the pain of ischaemic muscle, but did not find it as useful as amidone for this purpose. They also reported some analgesic action in sciatica, but their cases were not sufficiently numerous for analysis.

Various General Measures.-In attempts to override the evasive aetiological factors at work in rheumatism, drugs are sometimes used which in their effects of producing fever and leucocytosis simulate the natural defence mechanism of the body. On other occasions substantial doses of endocrines, vitamins, and other physiological substances have been given. Leucocytosis can be sustained by drugs for short periods only. That following the injection of sodium nucleinate or pentnucleotide fades away after a week of daily medication. Sulphur by vein causes a substantial increase in the polymorphonuclear count, but its duration is only a matter of hours and injections cannot be repeated many times. Pyrexia accompanies the sulphur leucocytosis and it has sometimes been thought that the combined effects of fever and leucocytosis have been helpful. Colloidal sulphur injected intramuscularly produces a similar dual response of less intensity, but may lead to considerable damage to the muscle. It is now agreed that the pharmacological reactions are inconstant and the clinical effects uncertain so that in spite of the early enthusiasm of Cawadias the Council on Pharmacy of the American Medical Association reported that by 1933 the practice of injecting sulphur into either the muscles or the veins had almost been abandoned in America.
Endocrines.-A rheumatic patient with welldefined endocrine defects is greatly benefited by their correction. Some years ago it was the vogue to prescribe small doses of thyroid preparations in the chronic and subacute phases of rheumatoid arthritis irrespective of whether there were clinical signs of deficiency or not. This led to little good and cannot be recommended, but spectacular success often follows thyroid medication in myxoedematous rheumatic subjects. Sex hormones have also been tried extensively, especially oestrogenic ones in women for arthritis arising during the menopausal decade. It had been expected that they might be of particular value in that somewhat ill-defined clinical group styled climacteric arthritis, which affects principally the knees and the small joints of the fingers, but no consistent results have been obtained. Coste and others (1948) used hexoestrol, $5 \mathrm{mg}$., and alternatively stilboestrol, $3 \mathrm{mg}$. to $4 \mathrm{mg}$., daily for ten consecutive days each month and noted a transient diminution in symptoms in a little more than half of his 205 osteo-arthritic patients. Pierre-Weil and Sichère (1948) used implants of oestradiol and progesterone and record a reduction in pain in 50 per cent. of menopausal and post-menopausal women with osteo-arthritis. It would appear that some advantage can on occasion be secured by the method in these intractable cases, but if oestrogens are administered too generously the endometrium becomes hyperplastic and troublesome uterine haemorrhage occurs. Administration must be carefully supervised. The following dosage schemes are appropriate but no final recommendations can be made: (1) injections of natural oestrogen, 50,000 international benzoate units twice a week for several weeks after which the dose should be systematically reduced; (2) synthetic dinoestrol by mouth, $\mathbf{0 . 3} \mathrm{mg}$., or ethinyl oestradiol, $0.05 \mathrm{mg}$. daily for nine or ten consecutive days in each month over a span of three or four months in all. (See also p. 97 of this issue.)

Vitamins.-Variations in the prothrombin-content of the blood are of frequent occurrence during rheumatic fever. Their relationship to salicylate medication is not simple. Significant falls may take place before salicylate therapy has been instituted or may be found during the administration of the drug and may correct themselves spontaneously even though the course of mild or massive salicylate dosage is not interrupted (Owen and Bradford 1946). There would appear to be little justification for giving vitamin $\mathrm{K}$ or its analogues as a routine adjunct to salicylates. Vitamin $\mathbf{K}$ could logically be reserved for definite hypothrombinaemia complicated by haemorrhage and for those rare occasions 
when surgical operation is contemplated for a rheumatic patient in a hypothrombinaemic phase.

The dietetic restrictions commonly imposed on rheumatic patients expose them to the risk of primary vitamin deficiencies which can easily be made good with supplementary vitamin concentrates. Vitamin $D$ has been employed for different reasons in massive dosage in the treatment of a variety of conditions; including several forms of arthritis. By an inductive method of reasoning it was surmised that it might normalize bony growth and metabolism in the affected parts, re-calcify the rarefied areas, and generally increase resistance to microbe invasion, but the clinical results do not bear out such hopeful anticipation. Calciferol, 50,000 i.u. daily for a week and then at two-day intervals, has been used without much evidence of harm, but in the treatment of arthritis daily doses up to 600,000 i.u. have been advised and these may cause renal failure and serious and even fatal metastatic deposits of calcium in the soft tissues. Ostelin (high-potency) was given by Lightbound (1948) in 150,000 i.u. daily by mouth or 600,000 i.u. intramuscularly twice a week for six months without disaster. The kidney function was impaired in all cases, and hxpercalcaemia associated with symptoms of toxic action commonly occurred. The ostelin appeared to be better tolerated when injected than when given orally. The tendency of irradiated ergosterol to produce such lesions is greatly influenced by the circumstances in which irradiation has been carried out, and it was hoped that the special method employed in producing the American variety Ertron would overcome the difficulties. Giving Ertron in 150,000 U.S.P. units (U.S.P. units are equivalent to international units) daily and increasing the dose very gradually to 300,000 units, Norris (1947) reported improvement in pain and swelling in about half of his forty miscellaneous cases of predominantly rheumatoid types. Gastric disturbances occurred frequently, but no other adverse reactions were noted. Nevertheless, fatalities from massive metastatic deposits of calcium salts have occurred amongst arthritic patients receiving this preparation (Kaufman and others, 1947; Bevans and Taylor, 1947), and the procedure should definitely be regarded as a dangerous one and its advantages in rheumatism problematical.

\section{Summary}

The medicinal measures of most proven worth in the treatment of rheumatoid arthritis and other rheumatic conditions of chronic inflammatory type are those concerned with (1) cleansing areas of surface infection, (2) correcting alimentary aberrations, (3) maintaining the efficiency of vital functions, (4) relieving pain and distress, and (5) chrysotherapy.

Other methods have been examined; some have been discarded and others hopefully recommended for further research and trial.

(The above summary refers to the section of this article dealing with the rheumatoid group, and not to the paper as a whole, which does not seem to lend itself to helpful condensation.)

\section{REFERENCES}

Ahlmark, A. (1944). Acta physiol. scand., 9, Supplement 28 .

Anrep, G. V., Barsoum, G. S., and Ibrahim, A. (1947). J. Physiol., 106, 379.

Appelqvist, O., and Holsti, O. (1947). Schweiz. med. Wschr., 77, 977.

Baker, D. M., and Chayen, M. S. (1948). Lancet, 1, 93.

Barsi, I. (1947). Brit. med. J., 2, 252.

Bélisle, M. (1948). Un. méd. Can., 77, 392.

Berg, R. (1928). Biochem. Z., 198, 424.

Berger, F. M., and Bradley, W. (1946). Brit. J. Pharmacol., 1, 265

- - - (1947). Lancet, 1, 97.

Berger, F.. M., and Schwartz, R. P. (1948). J. Amer med. Ass., 137, 772.

Bevans, M., and Taylor, H. K. (1947). Amer. J. Path., 23, 367.

Brendstrup, P. (1948). Ugeskr. Lag., 110, 948.

Bloch, L., and Rosenberg, D. H. (1934). Amer. J. Digest. Dis., 1, 29.

Bowen, B. D., Roufa, J. F., and Clinger, O. W. (1936). J. Amer. med. Ass., 107, 276.

Brown, T. McP. and Nunemaker, J. C. (1942). Bull. Johns Hopk. Hosp., 70, 201.

Coburn, A. F. (1943). Ibid., 73, 435.

$\longrightarrow$, and Moore, L. V: (1939). J. clin. Invest., 18, 147.

Cohen, A., Goldman, J., and Dubbs, A. W. (1947). J. Amer. med. Ass., 133, 749.

Coste, F., Lacronique, A., and Hochfeld, M. (1948). Rev. Rhum., 15, 40.

Crowe, H. W. (1944). Lancet, 1, 563.

Dameshek, W., and Colmes, A. (1936). J. clin. Invest., $15,85$.

Dixon, W. E., and Hoyle, C. (1921). J. pharm. exp. Therap., 35, 409.

Dry, T. J., Butt, H. R., and Scheifley, C. H. (1946). Proc. Mayo Clin., 21, 497.

Eisleb, O., and Schaumann, O. (1939). Dtsch. med. Wschr., 65, 967.

Feldt, A. (1926). Klin. Wschr., 5, 299.

Fenz, E. (1941). Munch. med. Wschr., 88, 1101.

Findlay, G. M., Mackenzie, R. D., and McCallum, F. O: (1940). Brit. J. exp. Path., 21, 13.

Fischel, E. E. (1947). Proc. Soc. exp. Biol. N.Y., 66, 537.

Forbes, G. (1947). Brit. med. J., 1, 367.

Forestier, J. (1929). Bull. mém. Soc. méd. Hôp. Paris, $53,323$.

$\longrightarrow$, and Certonciny, A. (1946). Presse med., 54, 884. , (1947). Rev. Rhum., 14, 271.

_ Jacqueline, F., and Lenoir, S. (1948). Presse méd., $56,351$.

Gebert, K. (1931). Z. klin. Med., 117, 147.

Gersdorff, W. A., and Smith, L. E.'(1940). Amer. J. Pharm., 197. 
Griffith, G. C. (1947). J. Amer. med. Ass., 133, 974.

Guerra, F., and Gil, J. R. (1946). Arch. Inst. Cardiol. Mex., 16, 293.

-, (1947). Ibid., 17, 733.

Hanzlik, P. J., Lehman, A. J., and Richardson, A. P. (1937). Amer. J. Syph., $21,1$.

,$- \frac{62}{54 .}$ (1938). J. Pharmacol. exp. Therap.,

Harris, T. N. (1947). Amer. J. med. Sci., 213, 482.

Hartung, E. F., and Cotter, J. (1941). J. Lab. clin. Med., 26, 1274 .

Heilman, F. R. (1940). Science, 91, 366.

Hench, P. S. (1938). Arch. int. Med., 61, 451, 495.

Hewer, A. J. H., and Keele, C. A. (1947). Lancet, 2,281 .

Heymans, C., and de Vleeschhouwer, G. R. (1948). Arch. int. Pharmacodyn., 75, 307.

Kaufman, P., Beck, R. D., and Wiseman, R. D. (1947). J. Amer. med. Ass., 134, 688.

Klarmann, E., Shternov, V. A., and Gates, L. W. (1934). J. Lab. clin. Med., 19, $835 ; 20,40$.

Koppenhöfer, G. F. (1935). Beitr. klin. Tuberk., 86, 549.

Kron, R. (1948). Schweiz. med. Wschr., 78, 80.

Leon, M. de (1948). Ned. Tijdschr. Geneesk., 92, 2084.

Lightbound, Teresa (1948). Lancet, 2, 1010.

Lucchesi, M., and Lucchesi, O. (1946). Hospital, Rio J., 30, 951 .

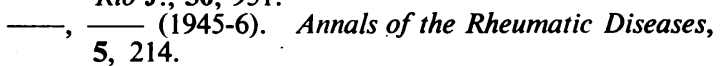

MacBryde, C. M. (1940). J. Amer. med. Ass., 114, 316.

Machle, W., Deichmann, W., and Thomas, G. (1943). J. industr. Hyg., 25, 192.

Macleod, J. G. (1948). Annals of the Rheumatic Diseases, 9, 143.

Mallory, F. B. (1926). Arch. int. Med., 37, 336.

Manchester, R. C. (1946). Ibid., 78, 170.

Mayer, R. L., and Kull, F. C. (1947). Proc. Soc. exp. Biol., N.Y., 66, 392.

Meleney, F. L., Johnson, B. A., and Pulaski, E. J. (1946). J. Amer. med. Ass., 130, 121.

Meyer, K., and Ragan, C. (1948). Science, 108, 281.

Mutch, N. (1934). J. Pharmacol., 51, 112. (1944). Lancet, 2, 775.

(1946). Quart.J. Pharm. Pharmacol., 19, 490.

Mutch, N., and Rewell, R. E. (1945). Lancet, 1, 650.

Norris, G.'(1947). Rheumatism, 3, 106.

Nyström, G. (1948). Nord. Med., 37, 499.

Owen, G. C., and Bradford, H. A. (1946). Ann. int. Med., 25, 97.

Peters, R. A., and others (1947). Brit. med. J., 2, 520.

Pierre-Weil, M., and Sichère, R. (1948). Rev. Rhum., $15,33$.

Ragan, C., and Boots, R. H. (1947). J. Amer. med. Ass., 133, 752.

Reid, J. (1948), Quart. J. Med., 17, 139.

Renshaw, A. (1947). Annals of the Rheumatic Diseases, $6,15$.

Rosenblum, H., and Fraser, L. E. (1947). Proc. Soc. exp. Biol. N.Y., 65, 178.
Rothbard, S., Angevine, D. M., and Cecil, R. L. (1941). J. Pharmacol., 72, 164.

Sabin, A. B., and Warren, J. (1941). J. Amer. med. Ass., $117,1561$.

Schiemann, O., and Feldt, A., (1926). Z. Hyg. Infekt. $K r ., 106,83$.

Schiffrin, M. J., and Komarov, S. A. (1941). Amer. J. Digest. Dis., 8, 215.

Scott, C. C., Kohlstaedt, K. G., and Chen, K. K. (1947). Curr. Res. Anaesth:, 26, 12.

Simpson, N. R. W. (1948). Brit. med. J., 1, 545.

Slot, G., and McDonald, A. D. (1947). Ibid., 2, 773.

Snyder, R. G., and others (1935). Proc. Amer. Ass. Study and Control of Rheum. Dis., 2, 101.

Sollmann, T., Cole, H., and Henderson, K. (1938). Arch. Derm. Syph. Chicago, 37, 993.

Stokes, H. L. (1947). Proc. R. Aust. Coll. Phys., 2, 16.

Sundelin, F. (1948). Nord. Med., 37, 303.

Svartz, N. (1948). Ibid., 37, 299.

- (1948). Bull. Schweiz. Aked. med. Wiss., 3, 311.

Swyer, G. I. M. (1948). Biochem. J., 42, 28.

Thomas, C. B., and France, R. (1939). Bull. Johns Hopk. Hosp., 64, 67.

Tompsett, S. L. (1934). Biochem. J., 28, 1544, 2088.

Trommer, P. R., and Cohen, A. (1944). J. Amer. med. Ass., 124, 1237.

Umber, F. (1929). Med. Welt., 3, 593, 633.

U.S. Naval Medical Research Unit (1948). U.S. Nav. med. Bull. Wash., 48, 380.

Warren, H. A., Higley, C. S., and Coombs, F. S. (1946). Amer. Heart J., 32, 311.

Waugh, W. G. (1938). Lancet, 1, 487. (1946). Brit. med. J., 2, 876.

White, E. P. C. (1931). J. Lab. clin. med., 17, 17.

Wilson, 'W. M., and Hunter, R. B. (1948). 'Brit. med. J., 2, 553.

Wilson, C. E., Hammond, C. W., Byrne, A. F., and Bliss, E. A. (1945). Bull. Johns Hopk. Hosp., 77, 411.

\section{Traitement Médical de Troubles Rhumatismaux RÉSUMÉ}

Les médicaments qui sé sont montrés les plus actifs dans le traitement de l'arthrite rhumatismale et d'autres affections rhumatismales du type inflammatoire chronique sont celles dont le rôle consiste (1) à nettoyer les foyers d'infection superficiels, (2) à corriger les fautes alimentaires, (3) à maintenir la bonne marche des fonctions vitales, (4) à soulager la douleur et relever le moral du malade, (5) et la chrysothérapie.

D'autres méthodes ont été étudiées; certaines ont été rejetées, et d'autres sont recommandées pour une étude plus approfondie.

(Le résumé ci-dessus se rapporte à la partie de cet article qui a trait au groupe des affections rhumatismales, et non à l'ensemble de l'article, qui ne se résumé pas aisément.) 